\title{
MODEL PELATIHAN GURU IPS, IPA TEMATIK TERPADU KURIKULUM 2013 DI SEKOLAH DASAR MUHAMMADIYAH KARTASURA
}

\author{
Tjipto Subadi ${ }^{1)}$, Budi Murtiyasa ${ }^{2)}$, Sutama ${ }^{3)}$, Anam Sutopo ${ }^{4)}$, Muhroji ${ }^{5)}$ \\ ${ }^{1)}$ Pendidikan Geografi , ${ }^{2)}$ P) Pendidikan Matematika , ${ }^{4)}$ Pendidikan Bahasa Inggris \\ ${ }^{5}$ Pendidikan PGSD \\ Fakultas Keguruan dan Ilmu Pendidikan \\ Universitas Muhammadiyah Surakaeta \\ e-mail : tjipto.subadi@ums.ac.id
}

\begin{abstract}
The Aim of community service are; 1) Training of primary school teachers of Social Sciences, Natural Sciences based integrated thematic curriculum in 2013 with a scientific approach, 2) To improve the professional skills of primary school teachers of Social Sciences, Natural Sciences based integrated thematic curriculum in 2013 with a scientific approach, 3) To produce the guidance system of the teachers of Social Sciences, Natural Sciences based integrated thematic curriculum, 2013 in Muhammadiyah schools Kartasura. This is the approach of community service workshops, training and mentoring learning of Social Sciences, Natural Sciences based integrated thematic curriculum, 2013. The participants of Master of Social Sciences, Natural Sciences in SD Muhammadiyah Kartasura, His place in the School of Muhammadiyah Kartasura. The result of this devotion implementation; 1) Training of primary school teachers of Social Sciences, Natural Sciences based integrated thematic curriculum in 2013 with a scientific approach, using techniques to observe, to question, to reason, to try and form a network, and implemented with the collaboration system, using the three steps of the learning; introductory, core and cover. 2) To improve the professional skills of primary school teachers of Social Sciences, Natural Sciences based integrated thematic curriculum in 2013 with a scientific approach, using cooperative learning model learning with instructional strategies PBL (Problem Based Learning), DCL (descovery Learning), Jigsaw. Third this learning strategy, capable of creating a class to become a haven for students, namely; happy atmosphere for learners in the following study. This learning strategies, can improve learning achievement, namely; No increase in the value pretest to posttest values, namely: pretest values $>60=50 \%$ : postes values $>69=100 \%$. 3) The resulting model of training primary school teachers of Social Sciences, Natural Sciences based integrated thematic curriculum in 2013 is a model mentoring based learning lesson study, with three stages (plan-do-see).
\end{abstract}

Kata kunci: lesson, study, model, pelatihan, guru 


\section{PENDAHULUAN}

Kurikulum tahun 2013 yang dikenal dengan K 13 adalah kurikulum hasil penyempurnaan KTSP (Kurikulum Tingkat Satuan Pendidikan). Kurikulum ini juga disebut Pendidikan Berbasis Karakter. Penyempurnaan terdiri dari penyerdehanaan, tematik-integratif, dan penambahan jam pelajaran. Perubahan mendasar adalah dikuranginya beberapa mata pelajaran di jenjang SD dan SMP, serta dihilangkannya sistem penjurusan pada jenjang SMA (Diknas, 2013). ${ }^{[1]}$ Penghilangan sistem penjurusan bertujuan untuk menghilangkan anggapan bahwa jurusan IPA itu untuk anak pintar sedangkan IPS dan bahasa itu untuk anak kurang mampu. Dengan K 13 ini, setiap siswa atau peserta didik diharapkan mampu melakukan observasi, bertanya, menalar, dan mengkomunikasikan (mempresentasikan) apa yang sedang mereka pelajari. Tujuannya supaya siswa dapat lebih kreatif, inovatif, dan lebih produktif.

Terdapat 3 aspek dalam K 13 ini, yaitu; aspek pengetahuan, aspek keterampilan, dan aspek sikap. Aspek pengetahuan pada $\mathrm{K} 13$ penekanannya pada tingkat pemahaman siswa dalam pembelajaran, aspek pengetahuan ini tidak ada perbedaan dengan kurikulum-kurikulum sebelumnya, hanya aspek pengetahuan pada K 13 tidak lagi menjadi aspek utama. Aspek keterampilan pada K 13 penekanannya pada kemampuan siswa untuk berpendapat, berdiskusi, membuat laporan, dan mempresentasikan apa yang sedang dipelajari, dengan aspek ini, siswa diharapkan tidak hanya tahu teori saja. Aspek sikap pada K 13 meliputi sopan santun, kedisiplinan, sosial, dan agama, aspek ini sangat sulit untuk dinilai karena guru tidak dapat memantau seluruh siswanya setiap saat, sehingga terkadang penilaian sikap menjadi tidak efektif, oleh karena itu menilai sikap ditekankan pada perilaku yang menonjol pada setiap individu siswa.
Secara sederhana Kurikulum bisa dipahami sebagai alat untuk mencapai tujuan pendidikan, maka arah pendidikan terdapat dalam tujuan pendidikan Indonesia. Tujuan pendidikan Nasional dalam UU Nomor 2 Tahun 1989 Pasal 4 adalah "Mencerdaskan kehidupan bangsa dan mengembangkan manusia Indonesia seutuhnya, yaitu manusia yang beriman dan bertaqwa terhadap Tuhan Yang Maha Esa dan berbudi-pekerti luhur, memiliki pengetahuan dan ketrampilan, kesehatan jasmani dan rohani, kepribadian yang mantap dan mandiri serta rasa tanggung-jawab kemasyarakatan dan kebangsaan.”.

Setiap bagian dari tujuan pendidikan ini dicapai dengan cara menuangkannya dalam bentuk kurikulum. Misalnya, untuk mewujudkan manusia Indonesia yang beriman dan berbudi pekerti luhur dirancang mata pelajaran agama dan pendidikan Pancasila. Demikian juga untuk mewujudkan pengetahuan dan keterampilan, dirumuskan kompetensi-kompetensi yang perlu dimiliki peserta didik dalam setiap mata pelajaran. Namun, rumusan kurikulum perlu dimengerti sebagai produk sosial. Sejak awal sekali dicanangkan, kurikulum melibatkan sejumlah interaksi sosial dengan berbagai pihak. Dalam memahami dan mengimplementasi kannyapun, seharusnya melibatkan interaksi yang lebih intens. Apalagi, sebaik apa pun kurikulum dirumuskan, tak akan bermakna bila pada tahap implementasinya tidak baik. (Suara Guru, 2015). ${ }^{[2]}$

Kurikulum 2013 selain menggunakan pendekatan sintifik juga menggunakan pembelajaran tematik terpadu, pembelajaran ini dilaksanakan dengan menggunakan prinsip pembelajaran terpadu. Pembelajaran terpadu menggunakan tema sebagai pemersatu kegiatan pembelajaran yang memadukan beberapa mata pelajaran sekaligus dalam satu kali tatap muka. Pembelajaran tematik terpadu bermanfaat 
untuk memberikan pengalaman yang bermakna bagi peserta didik, karena saat peserta didik memahami berbagai konsep selalu melalui pengalaman langsung dan menghubungkannya dengan konsep lain yang telah dikuasai sebelumnya. Pembelajaran tematik terpadu dilaksanakan dengan menggunakan prinsip pembelajaran terpadu. Pembelajaran terpadu menggunakan tema sebagai pemersatu kegiatan pembelajaran yang memadukan beberapa mata pelajaran dalam satu kali tatap muka.

Dalam implementasinya, perlu dilakukan berbagai studi yang mengarah pada peningkatan efisiensi dan efektivitas layanan dan pengembangan sebagai konsekuensi dari suatu inovasi pendidikan. Salah satu bentuk efisiensi dan efektivitas implementasi kurikulum, perlu dikembangkan berbagai model pembinaan guru melalui worksop dan pelatihan dalam upaya perolehan keutuhan belajar, pengetahuan, serta kebulatan pandangan tentang kehidupan dan dunia nyata yang hanya dapat direfleksikan melalui pembelajaran terpadu (Nasar, 2006). ${ }^{[3]}$

Sekolah-sekolah Muhammadiyah Kartasura sebagai mitra pengabdian masyarakat dengan P3G FKIP Universitas Muhammadiyah Surakarta menghadapi berbagai masalah, dan jika mengacu pada analisis situasi prioritas permasalahan yang dihadapi oleh guru-guru sekolah mitra sebagaian besar belum pernah mendapatkan pelatihan implementasi kurikulum 2013. P3G terpanggil mengambil bagian dan bekerja sama dengan Majlis Dikdasmen Muhammadiyah Cabang Kartasura untuk mengadakan kegiatan workshop dan pelatihan Model Pembinaan Guru SD IPS IPA Tematik Terpadu K 13 tersebut.

Permasalahan yang muncul adalah:

1. Bagaimana model pembinaan guru SD IPS, IPA tematik terpadu berbasis Kurikulum 2013 dengan pendekatan saintifik,
2. Bagaimana cara meningkatkan kemampuan professional guru SD IPS, IPA tematik terpadu berbasis Kurikulum 2013 dengan pendekatan saintifik,

3. Bagaimana sistem pembinaan guru-guru SD IPS, IPA tematik terpadu berbasis Kurikulum 2013 di sekolah-sekolah Muhammadiyah Kartasura sebagai mitra.

Tujuan pengabdian kepada masyarakat ini:

1. Pembinaan guru SD IPS, IPA tematik terpadu berbasis Kurikulum 2013 dengan pendekatan saintifik,

2. Meningkatkan kemampuan professional guru SD IPS, IPA tematik terpadu berbasis Kurikulum 2013 dengan pendekatan saintifik,

3. Menghasilkan model dan sistem pembinaan guru SD IPS, IPA tematik terpadu berbasis Kurikulum 2013 di sekolah-sekolah Muhammadiyah Kartasura sebagai mitra.

Bergantinya kurikulum sebagai inovasi pendidikan perlu disikapi sedini mungkin agar praktisi pendidikan tidak mengahadapi kesulitan ketika harus melaksanakan diberlakukan nya kurikulum baru (2013) ini. Pembelajaran IPS, IPA tematik terpadu menjadi bagian tak terpisahkan dari sistem kurikulum 2013, guru perlu berbenah diri untuk menyesuaikan perkembangan ilmu dan teknologi yang semakin berkembang di era glabal ini.

Kurikulum 2013 menggunakan pendekatan saintifik, pendekatan ini sangat relevan dengan teori belajar Bruner, Piaget, dan Vygotsky berikut ini. Teori belajar Bruner disebut juga teori belajar penemuan. Ada empat hal pokok yang berkaitan dengan teori belajar Bruner (Carin \& Sund, 1975) $)^{[4]}$. Pertama, individu hanya belajar dan mengembangkan pikirannya apabila ia menggunakan pikirannya. Kedua, dengan melakukan proses kognitif dalam proses 
penemuan, peserta didik akan memperoleh sensasi dan kepuasan intelektual yang merupakan suatu penghargaan intrinsik. Ketiga, satu-satunya cara agar seseorang dapat mempelajari teknik-teknik dalam melakukan penemuan adalah ia memiliki kesempatan untuk melakukan penemuan. Keempat, dengan melakukan penemuan, retensi ingatan peserta didik akan menguat. Empat hal di atas bersesuaian dengan proses kognitif yang diperlukan dalam pembelajaran dengan pendekatan saintifik.

Pendekatan saintifik/pendekatan berbasis proses keilmuan merupakan pengorganisasian pengalaman belajar meliputi: Mengamati (observing), menanya, (Questioning), Mencoba (experimenting), mengolah, Menghubungkan (Associating), menyimpulkan, Mengomunikasi kan/ mengolaborasikan/jejaring (communicating/ cooperating/ networking).

Selain pendekatan saintifik Kurikulum 2013 juga menggunakan pembelajaran tematik terpadu, pembelajaran ini dilaksanakan menggunakan prinsip pembelajaran terpadu. Pembelajaran terpadu menggunakan tema sebagai pemersatu kegiatan pembelajaran yang memadukan beberapa mata pelajaran sekaligus dalam satu kali tatap muka. Pembelajaran tematik terpadu bermanfaat untuk memberikan pengalaman yang bermakna bagi peserta didik, karena saat peserta didik memahami berbagai konsep selalu melalui pengalaman langsung dan menghubungkannya dengan konsep lain yang telah dikuasai sebelumnya.

\section{METODE PELAKSANAAN}

Pendekatan yang digunakan untuk menyelesaikan persoalan yang dihadapi sekolah mitra dalam kurun waktu realisasi program Penakerja ini; 1) Workshop implementasi K 13 dengan materi; 2) Pelatihan (peer teaching) pembelajaran IPS, IPA tematik terpadu; 3) Pendampingan pembelajaran IPS, IPA tematik terpadu berbasis K 13 dengan pendekatan saintifik.

Tempat kegiatan pengabdian masyarakat di Ruang Sidang FKIP-UMS. Waktu kegiatan workshop dan pelatihan peer teaching pada Hari Sabtu-Ahad, 7-8 Oktober 2015, kemudian dilamjutkan pemdampingan pembelajaran di Sekolah mitra. Peserta pengabdian masyarakat ini adalah guru-guru SD IPS, IPA Sekolah Muhammadiyah Kartasura. Sedangkan sebagai Nara Sumber adalah Tim P3G FKIP- Universitas Muhammadiyah Surakarta.

Metode yang digunakan dalam workshop adalah ceramah, interaktif, tanya jawab, dan diskusi tentang; 1) Sosialisasi Kosep Dasar Kurikulum 2013 dan Penguatan Proses (proses pembelajaran dan proses penilaian IPS, IPA tematik terpadu berbasis Kurikulum 2013); 2) Sosialisasi pendekatan saintifik sebagai model pembinaan guru SD IPS, IPA tematik terbadu. 3) Pelatihan guruguru SD IPS, IPA tematik terpadu secara simulatif (peer teaching) berbasis Kurikulum 2013, dengan pendekatan saintifik. Produk pelatihan ini, antara lain: RPP IPS, IPA tematik terpadu, Pengembangan materi ajar, IPS, IPA tematik terpadu, Pengembangan instrumen evaluasi IPS, IPA tematik terpadu dan Penerapan strategi yang tepat dalam pembelajaran IPS, IPA tematik terpadu.

Kemudian dilakukan pendampingan implementasi Kurikulum 2013 pembelajaran IPS, IPA tematik terpadu berbasis saintifik oleh P3G FKIP UMS terhadap guru-guru sekolah mitra. Adapun pendampingan pembelajaran di kelas dengan jadwal sebagai berikut: 


\section{JADWAL PENDAMPINGAN PEMBELAJARAN IMPLEMENTASI KURIKULUM 2013 BERBASIS LESSON STUDY}

\begin{tabular}{|rlllll|}
\hline NO & Hari, tgl & Nama Guru & Sekolah & Nomor HP \\
\hline $\mathbf{1}$ & Senin, 23 Nov 2015 & Inti Rofiqoh & SDIT Muh. Al Kautsar & 085725138577 \\
\hline $\mathbf{2}$ & Senin, 30 Nov 2015 & Anjar Purwitosari & MI Muh. Pucangan & 085878871808 \\
\hline $\mathbf{3}$ & Selasa, 1 Des 2015 & Nur Fadlilah & SD Muh. Gonilan & 085229099399 \\
\hline $\mathbf{4}$ & Jumat, 4 Des 2015 & Eni Sholikhatun & MI Muh. Kertonatan & 08994252147 \\
\hline $\mathbf{5}$ & Sabtu, 5 Des 2015 & Umi Mahmudah & MI Muh. Wirogunan & 085647046028 \\
\hline $\mathbf{6}$ & Selasa, 12 Jan 2016 & Rohmadi & MI Muh. PK Kartasura & 085740372216 \\
\hline
\end{tabular}

\section{HASIL DAN PEMBAHASAN}

Hasil dari penelitian ini,

1. Pembinaan guru SD IPS, IPA tematik terpadu berbasis Kurikulum 2013 (K 13) dengan pendekatan saintifik.

Pembinaan guru SD IPS, IPA tematik terpadu berbasis K 13 dengan metode workshop, pelatiahan, dan pendampingan. Pendekatan yang digunakan adalah saintifik dengan teknik mengamati, menanya, menalar, mencoba dan membentuk jaringan. Dalam kegiatan workshop dan pelatihan ini para peserta berperan aktif baik pada waktu penyajian materi maupun pada saat kerja kelompok, bahkan pada saat peserta diberi waktu untuk bertanya, para peserta antusias dan banyak yang mengajukan perntanyaan seputar K 13, pertanyaan yang diajukan antara lain: Apa perbedaan mendasar Kurikulum 13 dengan Kurikulum KTSP? Apa benar kalau dikatakan bahwa sistem pembelajaran kurikulum sebelumnya tidak menggunakan pendekatan aktif learning? Mohon diberi contok tujuan pembelajaran yang yang spesifik dan yang umum yang terkait dengan KI KD? Mohon dijelaskan kembali urgensi tantangan internal, tuntutan pendidikan yang mengacu kepada 8 Standar Nasional
Pendidikan? Apa yang menjadi faktor sukses implementasi K 13? Apa harapan terhadap IN sebagai Narasumber terhadap implenetasi Kurikulu 2013? Bagaiaman perbedaan mendasar Kurikulum 2013 dengan Kurikulum sebelumnya?

Bagaimana penyempurnaan pola pikir K 13? Mohon penjelasan elemen utama perbaikan $\mathrm{K}$ 13? Mohon penjelaskan secara singkat proses penilaian dan yang terkait dengan penilaian K 13.

Dari banyaknya pertanyaan tersebut membuktikan bahwa para peserta sangat aktif dalam mengikuti workshop dan pelatihan K 13, para peserta sangat antusias dalam memahami K13. Penyaji (narasumber) kemudian menjawab pertanyaan-pertanyaan tersebut secara singkat.

Sebelum pelaksanaan workshop dan pelatihan peserta diberi pretes, hasilnya sebagaia berikut; dari 28 peserta yang mendapat nilai $>60=14$ orang (50\%), dan pada akhir workshop peserta diberikan pos tes, hasilnya dari 28 peserta yang mendapat nilai $>70=28$ orang $(100 \%)$, yang berarti pelaksanaan workshop dan pelatihan berhasil dengan predikat baik sekali. 
2. Peningkatan kemampuan professional guru SD IPS, IPA tematik terpadu berbasis Kurikulum 2013 (K 13) dengan pendekatan saintifik.

Implementasi pelaksanaan pembinaan guru tersebut menggunakan sistem kolaborasi, dengan tiga langkah pembelajaran, yaitu; pendahuluan, inti, dan penutup. Kegiatan pendahuluan, meliputi; orientasi, motivasi, apersepsi, dan menyampaikan tujuan. Kegiatan inti dengan menggunakan pendekatan saintifik (mengamati, menanya, menalar, mencoba dan membentuk jaringan). Sedangkan kegiatan penutup, meliputi; simpulan, refleksi, evaluasi/ penugasan, dan tindak lanjut.

$\mathrm{m}$ e $\mathrm{m} \mathrm{p}$ e r t i m b a $\mathrm{g} \mathrm{k}$ a $\mathrm{n}$ (menggunakan) model pembelajaran kooperatiflearning dengan multi strategi pembelajaran yaitu PBL (Problem Based Learning), DcL (Descovery Learning), dan Jigsaw. Ketiga strategi pembelajaran ini mampu menciptakan kelas menjadi surga bagi anak didiknya artinya anak kerasan, dan senang mengikuti pembelajaran, dan secara signifikan mampu meningkatkan kualitas perencanaan dan prestasi pembelajaran, indikatornya; a) Guru berkolaborasi dalam membuat RPP (Rencana Pelaksanaan Pembelajaran) lengkap dengan lampiran-lampirannya. b) Guru berkolaborasi menggunakan multi media. c) Guru berkolaborasi menggunakan strategi pembelajaran yang tepat. d) Guru berkolaborasi menggunakan pendekatan saintifik (mengamati, menanya, mencoba, mengolah, dan membuat jejaring. e) Guru berkolaborasi memberikan penilaian dengan pemperhatikan karakteristik belajar tuntas, autentik, berkesinambungan.

Pembinaan guru SD IPS, IPA tematik terpadu berbasis $\mathrm{K} 13$ dengan pendekatan saintifik ini bisa meningkatkan kemampuan professional guru. Terdapat peningkatan hasil (nilai) prites dengan postes, yakni nilai pretes yang dinyatakan lulus dengan nilai $>60$ sebesar $50 \%$ dan nilai postes yang dinyatakan berhasil dengan nilai $>70$ sebesar $100 \%$.

3. Model dan sistem pembinaan guru-guru SD IPS, IPA tematik terpadu berbasis Kurikulum 2013 di sekolah-sekolah Muhammadiyah Kartasura sebagai mitra. Pembinaan guru SD IPS, IPA tematik terpadu K 13 menghasilkan suatu model pembinaan. Adapun model yang dihasilkan dari pembinaan guru SD IPS, IPA tematik terpadu berbasis Kurikulum 2013 adalah model pendampingan berbasis lesson study. Model pendampingan pembinaan guru guru IPS IPA ini menggunakan tiga tahap (plando-see). Plan (Perencanaan) pruduknya RPP (Rencana Pelaksanaan Pembelajaran). Lampirannya; Lampiran pengembangan materi, Lampiran LKS (Lembar Kerja Siswa), Lampiran instrumen penilaian sikap; Lampiran instrumen penilaian pngetahuan; dan Lampiran instrumen penilaian ketrampilan. Do (Tindakan dan Observasi) yang meliputi Pendahuluan, Inti, dan Penutup. See (Refleksi) diskusi, evaluasi dan revisi.

Pembahasan tentang pembinaan guru SD IPS, IPA tematik terpadu berbasis K 13 dengan pendekatan saintifik menggunakan teknik mengamati, menanya, menalar, mencoba dan membentuk jaringa, dan implementasi pelaksanaannya menggunakan sistem kolaborasi, dengan tiga langkah pembelajaran, yaitu; pendahuluan, inti, dan penutup, pembinaan tersebut berpengaruh positif dan lebih efektif sebagai pembinanan guru profesional. Hal ini seperti yang disarankan Stephen L. Thompson (2007) ${ }^{[3]}$ dalam penelitian nya yang berjudul:'Inquiry 
in the Life Sciences: The Plant-in-a-Jar as a Catalyst for Learning berkesimpulan bahwa: 1) Adanya usaha guru untuk mengubah pola pembelajaran (modifikasi pola pembelajaran), hal ini berarti guru dituntut lebih kreatif dan inovatif. 2) Guru mencari terobosan untuk menyampaikan materi pelajaran pada KD tertentu agar pembelajaran menjadi lebih menyenangkan. 3) Usaha guru melakukan pembinaan pembelajaran sebagai referensi siswa bisa meningkatkan efektifitas pembelajaran. Thompson menyarankan, pentingnya pengembangan profesional guru yang lebih kreatif dan inovatif, yang dapat mempengaruhi pembelajaran sehingga menjadi pembelajaran yang menyenangkan dan demokratis.

Pembahasan tentang kegiatan pendahuluan, meliputi; orientasi, motivasi, apersepsi, dan menyampaikan tujuan. Kegiatan inti dengan menggunakan pendekatan saintifik (mengamati, menanya, menalar, mencoba dan membentuk jaringan). Sedangkan kegiatan penutup, meliputi; simpulan, refleksi, evaluasi/penugasan, dan tindak lanjut. Hal ini sejalan dengan pandangan Saito (2006) ${ }^{[4]}$ bahwa pada dasarnya kegiatan pembinaan guru dengan menggunakan lesson study ada tiga tahap, yaitu: Planning-Doing-Seeing. Tahap 1, Planning, pada tahap ini guru secara kolaborasi membuat rencana pembelajaran dengan skenarionya. Tahap 2, Doing, pada tahap ini guru model melaksanakan pembelajran dan guru yang lain menjadi observer, dalam pelaksanaan tindakan pembelajaran ini satuan waktu pembelajaran dibagi tiga yaitu; penyampaian pendahuluan, pembelajaran inti, dan mengakhiri pembelajaran. Tahap 3 Seeing, pada tahap ini para guru melakukan refleksi pembelajaran dan berdiskusi tentang pelaksanaan pembelajaran, mengevaluasi dan refisi pencanna pembelajaran serta memperbaikan pelaksanaan pembelajaran.
Sedangkan Pembinaan guru SD IPS, IPA tematik terpadu berbasis K 13 dengan pendekatan saintifik ini bisa meningkatkan kemampuan professional guru, secara signifikan mampu meningkatkan kualitas perencanaan dan hasil/prestasi pembelajaran dan terdapat peningkatan hasil (nilai) prites dengan postes, yakni nilai pretes yang dinyatakan lulus dengan nilai > 60 sebesar $50 \%$ dan nilai postes yang dinyatakan berhasil dengan nilai > 70 sebesar $100 \%$. Hal ini sejalan dengan penelitian Heni (2010) ${ }^{[5]}$ dalam Jurnal Sosial Humaniora Strategi, yang berjudul; Strategi Pembelajaran, Tipe Kepribadian dan Hasil Belajar Bahasa Indonesia pada Siswa Sekolah Menengah Pertama, berkesimpulan hasil penelitian menunjukkan bahwa (1) hasil belajar siswa yang mengikuti strategi pembelajaran kooperatif lebih tinggi dari pada yang mengikuti pembelajaran individual, (2) tidak ada perbedaan yang signifikan antara hasil belajar siswa yang berkepribadian ekstrover dan introver, (3) terdapat interaksi yang positif antara strategi pembelajaran dan tipe kepribadian siswa pada hasil belajar bahasa Indonesia, (4) hasil belajar siswa yang ekstrover, yang mengikuti strategi pembelajaran kooperatif lebih tinggi dari pada mengikuti strategi pembelajaran individual, (5) hasil belajar siswa yang introver, yang mengikuti strategi .

Pembahasan pembinaan guru SD IPS, IPA tematik terpadu K 13 menghasilkan suatu model pembinaan pendampingan berbasis lesson study. Model ini menggunakan tiga tahap (plan-do-see). Hal ini didukung pendapat Saito bahwa lesson study ini merupakan salah satu kegiatan pembelajaran bertujuan untuk meningkatkan kompetensi guru dan kualitas pembelajaran. Lesson study diartikan sebagai studi untuk analisis atas suatu praktik pembelajaran yang dilaksanakan dalam bentuk pembelajaran berbasis riset untuk menemukan inovasi pembelajaran tertentu. Dalam banyak 
literatur pembelajaran berbasis lesson study merupakan pembelajaran yang bersiklus, siklus dalam pembelajaran berbasis lesson study ini dilaksanakan dalam 3 (tiga) tahap, yaitu; "Plan" (merencanakan), "Do" (melaksanakan dan observasi), "See"

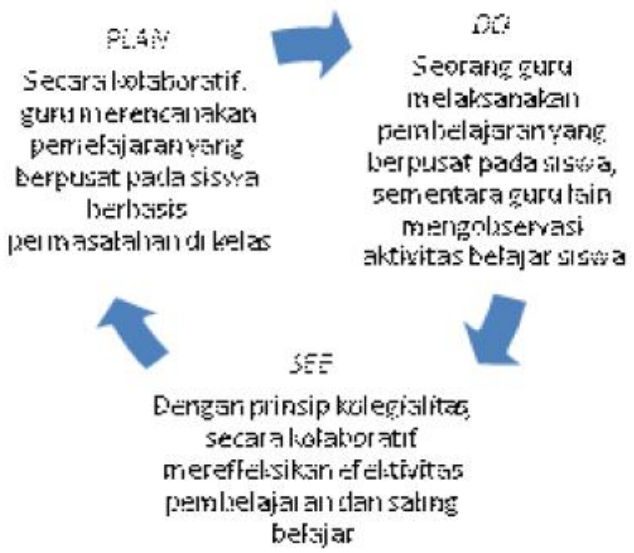

Gambar: Siklus Pembelajaran Berbasis Lesson Study

(Model Saito, 2006) bawah ini:

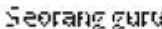

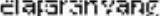
enientara rarditin mengolxsemasi

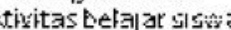

(merefleksi dan evaluasi), ketiga tahap tersebut dilaksanakan secara kolaborasi dan berkelanjutan (Saito, 2006). ${ }^{[6]}$ Secara sederhana dapat dilihat pada gambar di

Menurut Lewis (2002) ${ }^{[7]}$ ide yang terkandung di dalam lesson study sebenarnya singkat dan sederhana, yakni jika seorang guru ingin meningkatkan pembelajaran, salah satu caranya adalah guru harus mau berkolaborasi dengan guru lain untuk membuat rencana pembelajaran, melaksanakan pembelajaran dan observasi, melakukan refleksi dan evaluasi terhadap pembelajaran yang dilakukan. Dengan kata lain lesson study merupakan model pembinaan profesi pendidik melalui pengkajian pembelajaran secara kolaboratif dan berkelanjutan, berlandaskan prinsipprinsip kolegialitas dan saling membantu dalam pembelajaran untuk membangun komunitas belajar, lesson study adalah suatu proses sistematis yang digunakan oleh guruguru untuk menguji efektifitas pembelajaran untuk meningkatkan hasil pembelajaran, proses sistematis yang dimaksud adalah kerja guru-guru secara kolaboratif dalam mengembangkan rencana pembelajaran (lengkap dengan lampirannya), pelaksanaan refleksi, evaluasi dan revisi.

Apabila di mencermati konsep dasar lesson study, maka terdapat 7 (tujuh) kata kunci, yaitu; 1) pembinaan profesi, 2) pengkajian pembelajaran, 3) kolaborasi, 4) berkelanjutan, 5) kolegialitas, 6) mutual learning, dan 7) komunitas belajar. Tujuannya adalah untuk pembinaan profesi pendidik secara berkelanjutan agar terjadi peningkatan kualitas profesi pendidik secara terus menerus, sebab jika tidak dilakukan pembinaan terhadap guru, maka akan terjadi penurunan kualitas profesionalisme guru.

Temuan tersebut di atas juga sejalan dengan penelitian Subadi (2014) ${ }^{[8]}$ yang berjudul; Model Pembinaan Pendidik Profesional (Suatu Penelitian dengan Pendekatan Lesson Study pada Guru-Guru Sekolah Muhammadiyah Kabupaten Sukoharjo), yang berkesimpulan bahwa; 1) Validasi model pembinaan guru profesional melalui lesson study untuk mengatasi permasalahan pembelajaran di SD, SMP, SMA, SMK Muhammadiyah Kabupaten pembelajaran dan observasi, melakukan 
Sukoharjo adalah lesson study modifikasi empat tahap tiga siklus. Terdapat dua validasi lesson study sebagai model pembinaan guru, yaitu: a) Validasi lesson study kelas tertutup. b) Validasi lesson study kelas terbuka. 2) Sistem pendampingan implementasi pembelajaran berbasis lesson study sebagai model pembinaan guru di Sekolah Muhammadiyah Kabupaten Sukoharjo, menggunakan sistem pendampingan pendekatan, yaitu; empat tahap tiga siklus, pendekatan saintifik.

\section{SIMPULAN DAN SARAN}

\section{Simpulan}

a. Pembinaan guru SD IPS, IPA tematik terpadu berbasis K 13 dengan pendekatan saintifik menggunakan teknik mengamati, menanya, menalar, mencoba dan membentuk jaringan dan dilaksanakan dengan sistem kolaborasi, menggunakan tiga langkah pembelajaran, yaitu; pendahuluan, inti, dan penutup.

b. Untuk meningkatkan kemampuan professional guru SD IPS, IPA tematik terpadu berbasis Kurikulum 2013 dengan pendekatan saintifik menggunakan model pembelajaran kooperatif learning dengan strategi pembelajaran PBL (Problem Based Learning), DcL (Descovery Learning), Jigsaw. Ketiga strategi pembelajaran ini mampu menciptakan kelas menjadi surga bagi anak didiknya artinya anak kerasan, dan senang mengikuti pembelajaran. Secara signifikan mampu meningkatkan kualitas perencanaan dan hasil/prestasi pembelajaran.

Ada peningkatan hasil (nilai) prites dengan postes, yakni nilai pretes yang dinyatakan lulus dengan nilai > 60 sebesar $50 \%$ dan nilai postes yang dinyatakan berhasil dengan nilai $>69$ sebesar $100 \%$. c. Model yang dihasilkan dari pembinaan guru SD IPS, IPA tematik terpadu berbasis Kurikulum 2013 adalah model pendampingan berbasis lesson study. Model pendampingan pembinaan guru guru IPS IPA ini menggunakan tiga tahap (plan-dosee).

\section{Saran}

a. Workshop dan pelatihan implementasi Kurikulum 2013 perlu diupayakan oleh FKIP UMS, mengingat hal ini menjadi program pemerintah.

b. Lesson study diharapkan bisa dijadikan alternatif sebagai model pembinaan guru profesional, karena model ini sangat efektif dan mampu memberikan pengalaman pembelajaran berbasis saintifik.

c. Pembinaan pendidik secara profesional dengan pendekatan lesson study ini diharapkan dilaksanakan secara rutin dan berkesinambungan.

\section{PERSANTUNAN}

Pada kesempatan ini, tim pengabdian kepada masyarakat PENAKERJA menyampaikan banyak terima kasih kepada Yth:

1. Rektor Universitas Muhammadiyah, yang telah memberi kesempatan kepada tim pengabdian kepada masyarakat PENAKERJA untuk memperoleh dana pengabidian masyarakat ini.

2. Ketua LPPM Universitas Muhammadiyah Surakarta, yang telah meberikan vasilitas dan rekomendasi persetujuan proposal pengabdian masyarakat PENAKERJA ini untuk mendapatkan dana dari Universitas Muhammadiyah Surakarta.

3. Dekan FKIP yang telah memberi Surat Tugas kepada tim untuk melaksanakan pengabdian masyarakat ini. 


\section{DAFTAR PUSTAKA}

Depdiknas. 2014. Panduan Penguatan Proses Pembelajaran Sekolah Menengah Pertama. Kementerian Pendidikan Dan Kebudayaan Direktorat Jenderal Pendidikan Dasar Direktorat Pembinaan Sekolah Memengah Pertama

Ahmad Abror. 2015. Harian Suara Guru. Dalam http://www.harianguru.com/2015/10/ contoh-artikel-kurikulum-2013.html. di akses 13 Desember 2015.

Nasar. 2006. Merancang Pembelajaran Aktif dan Konstektual Berdasarkan "SISCO”2006. Jakarta : PT Gramedia Widiaksara.

Carin, A.A. \& Sund, R.B. 1975. Teaching Science Trough Discovery, $3^{\text {rd }}$ Ed Columbus: Charles E. Merrill Publishing Company

Thompson, 2007, Science Activities, Washington: Winter 2007. Vol. 43. Iss. 4, pg.27, 7 pgs.

Saito. E. 2006. Development of school based in-service teacher training under the Indonesian Mathematics and Science Teacher Education Project. Improving Schools. Vol.9 (1): 47-59

Heni Mularsih. 2010. Strategi Pembelajaran, Tipe Kepribadian Dan Hasil Belajar Bahasa Indonesia Pada Siswa Sekolah Menengah Pertama. Jurnal Makara, Sosial Humaniora, Vol. 14, No. 1, Juli 2010: 65-74

Saito. E. 2006. Op. Cit

Lewis, Catherine C. 2002. Lesson study: A Handbook of Teacher-Led Instructional Change. Philadelphia, PA: Research for Better Schools, Inc.

Subadi .2014. Medel Pembinaan Pendidik Profesional (Suatau Penelitian dengan Pendekatan Lesson Study pada Guru-Guru Sekolah Muhammadiyah Sukoharjo Tahun 3 (Laporan Penelitian Dipublikasikan di Perpustakaan Pusat UMS). 